\title{
Studies on the ion-beam modifications in ethylene diamine sulphate
}

\author{
E VENKATESHWAR RAO and M RAMAKRISHNA MURTHY* \\ Department of Physics, University College, Kakatiya University, Warangal 506 009, India
}

MS received 11 June 1998; revised 26 February 1999

\begin{abstract}
The growth features, defect'sub-structure and the influence of ion implantation on the (001) and (100) surfaces of ethylene diamine sulphate (EDS) single crystals have been studied. The surface micromorphology and defect substructure measurements of surface electrical conductivity and microhardness in both as-grown and $\mathrm{He}^{+}$ion-implanted surfaces of EDS have also been studied. Optical and scanning electron microscopic investigations on the (001) surface of EDS revealed octogonal mother-liquor inclusions and spiral and hopper growth features. Chemical etching of the (100) surface revealed an increase in dislocation density on ion implantation, the etch pit morphology remaining the same. Studies on planar plastic anisotropy in both (001) and (100) surfaces indicated the crystallographic nature of the single crystal. Enhancement of surface electrical conductivity on ion implantation has been attributed to the formation, migration and increase in $\mathrm{SO}_{4}^{-}$ion concentration relative to the as-grown EDS surfaces.
\end{abstract}

Keywords. Ion-implantation; surface micromorphology; surface electrical conductivity; microhardness; planar plastic anisotropy; ethylene diamine sulphate.

\section{Introduction}

Ion beam modifications have been studied on the physical properties of several organic molecular systems in view of the wide variety of applications such as in organic semiconductors, optoelectronic devices, organic phosphors etc (Mazzoldi and Arnold 1987). Organic materials in both amorphous and crystalline state have been investigated in such aspects as electrical conductivity (Kallman and Silver 1961), luminescence (Williams and Schadt 1970), and photoconduction and photovoltaic effects (Taylor and Simmons 1964). This paper presents the experimental investigations on single crystals of ethylene diamine sulphate (EDS) $\left[\left(\mathrm{NH}_{3} \mathrm{CH}_{2}\right)_{2} \mathrm{SO}_{4}\right]$.

EDS is an organic molecular system crystallizing in tetragonal system with base-centred unit lattice and with eight molecules per unit cell. Studies on surface micromorphology, surface conductivity and microhardness in EDS single crystals in both as-grown and ion-implanted surfaces have been carried out to understand the nature of damage on ion bombardment. Various techniques have been employed to understand the growth features, defect substructure, etch pit morphology, nature of charge carriers, crystallographic nature, etc.

\section{Experimental}

EDS supplied by the Central Drug House, New Delhi, was used. Single crystals were grown by slow evaporation of

*Author for correspondence saturated solution of EDS in distilled water. Good and optically transparent EDS single crystals were obtained with well-developed faces and cleavage in the (001) surface.

$\mathrm{He}^{+}$ion implantation of EDS surfaces was done using a medium energy ion scattering (MEIS) accelerator (ion beam energy of $150 \mathrm{keV}$ and current of $500 \mu \mathrm{A}$ ) at the facility created at the Materials Science Division of the Indira Gandhi Centre for Atomic Research, Kalpakkam with a dose rate of $\approx 10^{17}$ ions $/ \mathrm{cm}^{2}$. Ultra high vacuum in the range of $10^{-8}$ bar was provided in the irradiation chamber.

Scanning electron microscope (model S 250, MK-III, Cambridge) was employed to observe the growth features of EDS single crystals.

Chemical etching in both as-grown and ion-implanted surfaces was made employing a me-opta optical microscope. The depth of ion implantation, the spiral step height and the depth of chemical etching in EDS was around $500 \mathrm{~nm}$ as evaluated by interference microtopography.

Surface conductivity measurements in EDS surfaces were carried out employing a four-point probe method. The four contacts used to measure conductivity were of point contact type arranged as linear array. The surface on which probes rest was mechanically lapped to ensure good electrical contact. The probes had an equal spacing of $\approx 0.2 \mathrm{~cm}$ and the specimen was about $0.08 \mathrm{~cm}$ thick. Different voltages $(V)$ have been applied to the two outer probes and the resulting current $(I)$ measured by connecting a Keithley electrometer amplifier (model 610c), in 
series with two inner probes. Sample holder with four probes was kept in an oven, to vary the temperature of the specimen. The temperature was monitored to an accuracy of $\approx 1^{\circ} \mathrm{C}$ using a digital temperature controller. The temperature controller may be set to any desired temperature; the samples, however, were stabilized to these temperatures before the conductivity measurements. Conductivity $(\sigma)$ was evaluated using the equation $I / 2 \pi S V$, where $S$ is the probe spacing and $V$ the applied voltage.

Microhardness measurements and studies on planar plastic anisotropy were carried out using a Reichert microscope with Vicker's and Knoop indentors. The Vicker's hardness number was evaluated using the formula

$$
V_{\mathrm{HN}}=1.854 P / L^{2},
$$

and the Knoop hardness number evaluated using the formula
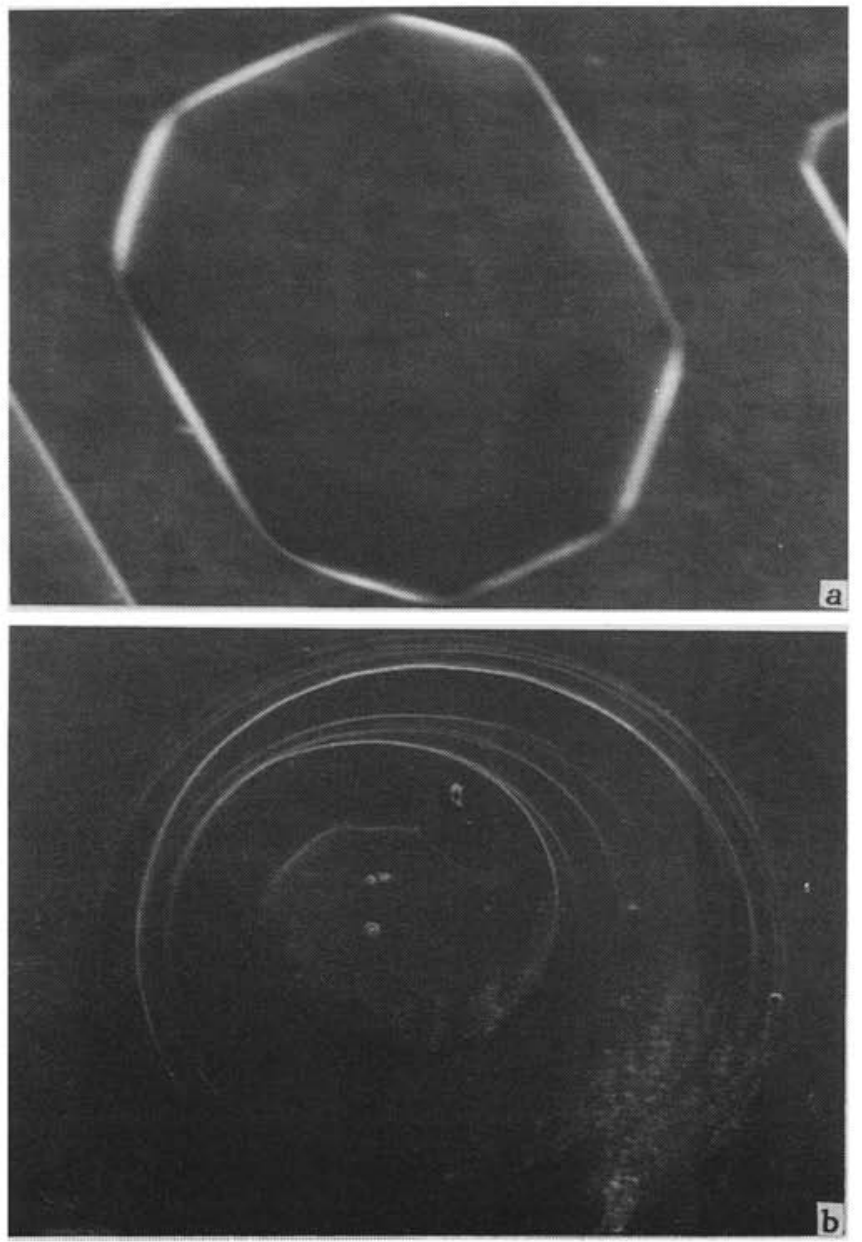

$$
K_{\mathrm{HN}}=1.43 P / L^{2},
$$

where $P$ is the load applied in $\mathrm{kg}$ and $L$ the length of longer diagonal in $\mathrm{mm}$.

\section{Results and discussion}

The scanning electron micrograph of the (001) surface of EDS single crystal (figure 1a), revealed the presence of octogonal mother liquor inclusions in the as-grown single crystals as observed by Hassan (1992).

The optical micrograph of the (100) surface of EDS (figure $1 \mathrm{~b}$ ), showed the formation of growth spirals, the apex of which is not clearly defined. The spiral step height determined by interference microtopography is found to be of the order of $500 \mathrm{~nm}$.

Optical micrograph of the chemical etch pits formed on (100) surface of EDS is shown in figure 1c. A mixture of methanol and water was employed as etchant. The optical
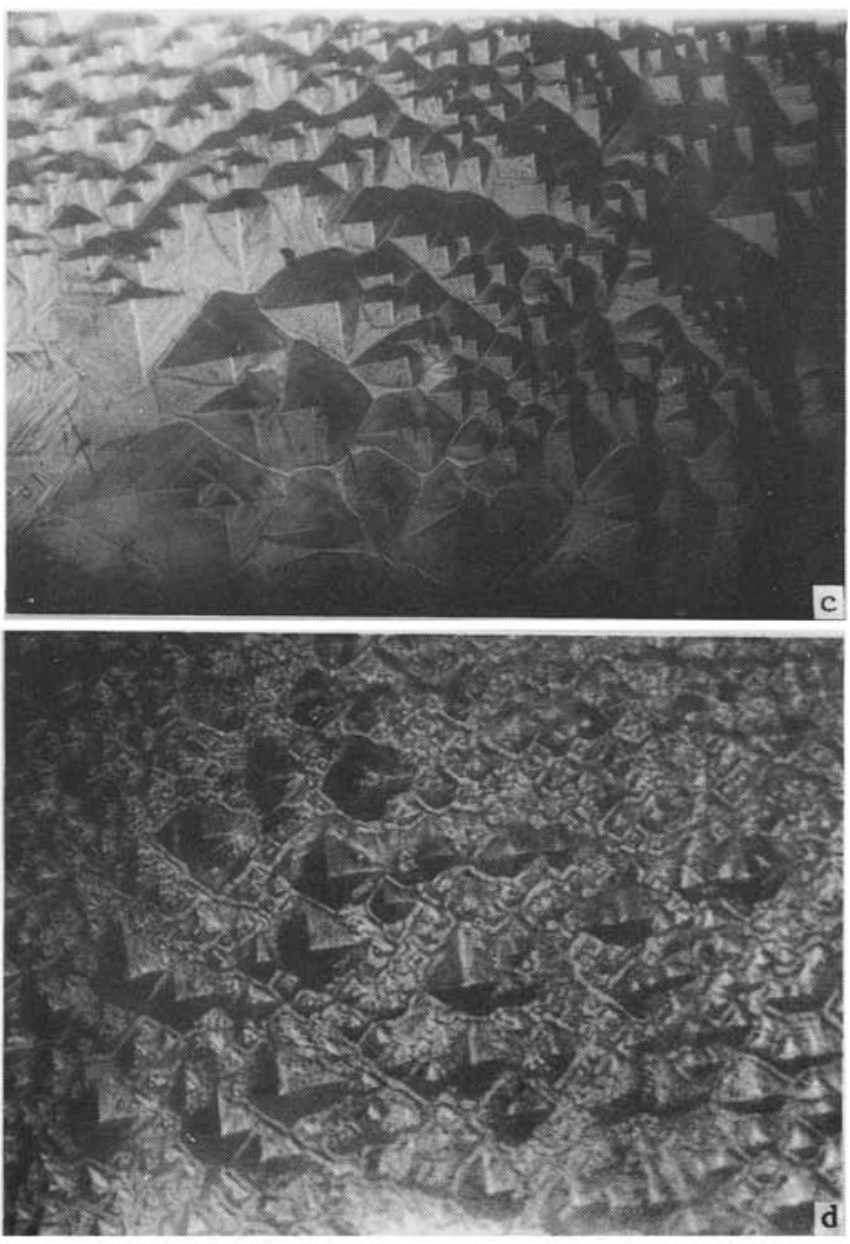
micrograph of the same surface, after ion implantation and subsequent chemical etching is shown in figure 1d. In both these conditions chemical etch pits with four-fold symmetry have been observed. While the etch pit morphology remained the same there was significant increase in dislocation density on ion implantation.

Optical micrographs of the Vickers indentor marks on the (100) in the as-grown and ion-implanted surfaces are shown in figures le and $1 \mathrm{f}$, respectively.

Microhardness measurements in both (100) and (001) surfaces of EDS, employing both Vicker and Knoop indentors (Mott 1956) with increasing loads are summarized in table 1 . In both cases, the hardness number decreased with increase in load for low loads but remained constant at higher loads.
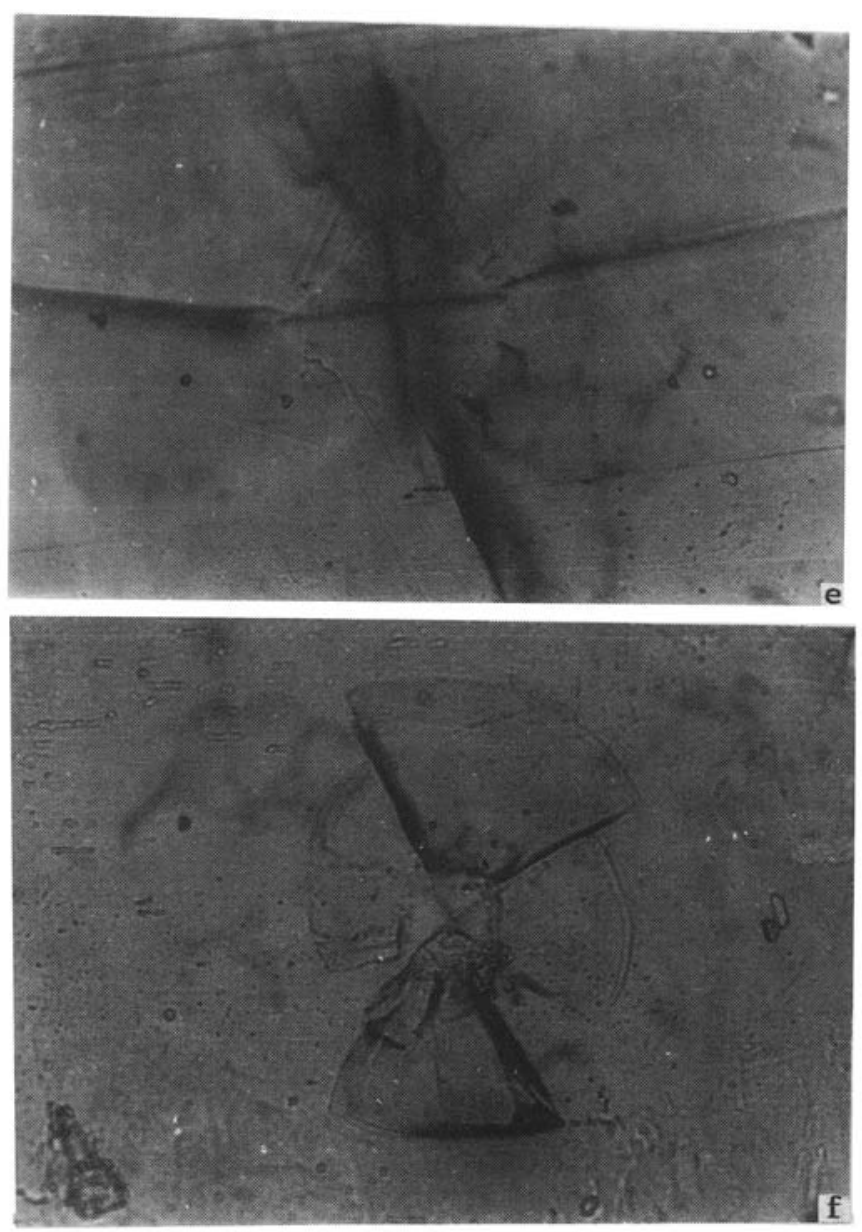

Figure 1. a-f. a, b. Scanning electron micrograph of (001) surface of EDS $(5500 \times[a] ; 200 \times[b])$. c, d. Optical micrographs of chemical etch pits formed on the (100) surface of EDS in (c) as-grown surface and (d) ion-bombarded surface. Etchant: methanol with water. e, f. Optical micrographs of Vicker indentor mark on the (100) surface of EDS, (e) as-grown and (f) ion-bombarded surface.
Microhardness measurements in both as-grown and ionbombarded surfaces are summarized in table 2. Planar plastic anisotropy in both (001) and (100) surfaces, and in as-grown and ion-implanted surfaces has been studied and the results depicted in figures 2 and 3 , respectively. For both surfaces, the microhardness increased on ion implantation of EDS and the hardness number showed systematic and drastic anisotropic effects in both the asgrown and ion-implanted surfaces.

Surface electrical conductivity $(\sigma)$ of (100) face of EDS has been measured at various temperatures in both as-grown and ion-bombarded surfaces employing fourpoint probe method (Runyan 1975). Arrhenius plots $\log \sigma$

Table 1. $H_{\mathrm{v}}, H_{\mathrm{k}}$ values for EDS single crystals.

\begin{tabular}{|c|c|c|c|}
\hline \multirow[b]{2}{*}{$\begin{array}{l}\text { Load } \\
\text { (g) }\end{array}$} & \multicolumn{2}{|c|}{$H_{\mathrm{v}}\left(\mathrm{Kp} \mathrm{mm}^{-2}\right)$} & \multirow{2}{*}{$\begin{array}{c}H_{\mathrm{k}}\left(\mathrm{Kp} \mathrm{mm}^{-2}\right) \\
(100) \\
\text { Surface }\end{array}$} \\
\hline & $\begin{array}{c}(100) \\
\text { Surface }\end{array}$ & $\begin{array}{c}(001) \\
\text { Surface }\end{array}$ & \\
\hline 5 & 70 & 98 & 38 \\
\hline 10 & 50 & 80 & 40 \\
\hline 15 & 40 & 67 & 37 \\
\hline 25 & 32 & 50 & 35 \\
\hline 50 & 23 & 40 & 32 \\
\hline 100 & 23 & 40 & 32 \\
\hline
\end{tabular}

Table 2. Planar plastic anisotropy of EDS single crystal.

\begin{tabular}{|c|c|c|c|c|}
\hline \multirow[b]{2}{*}{ Angle } & \multicolumn{2}{|c|}{$\begin{array}{c}\text { As-grown } \\
H_{\mathrm{k}}\left(\mathrm{K}_{\mathrm{p}} \mathrm{mm}^{-2}\right)\end{array}$} & \multicolumn{2}{|c|}{$\begin{array}{c}\text { Ion bombarded } \\
H_{\mathrm{k}}\left(\mathrm{K}_{\mathrm{p}} \mathrm{mm}^{-2}\right)\end{array}$} \\
\hline & $\begin{array}{c}(100) \\
\text { Surface }\end{array}$ & $\begin{array}{l}(001) \\
\text { Surface }\end{array}$ & $\begin{array}{l}(100) \\
\text { Surface }\end{array}$ & $\begin{array}{c}(001) \\
\text { Surface }\end{array}$ \\
\hline $0^{\circ}$ & 58.8 & 35 & $62 \cdot 5$ & 47 \\
\hline $45^{\circ}$ & $72 \cdot 6$ & 55 & $84 \cdot 2$ & 60 \\
\hline $90^{\circ}$ & 51.4 & 64 & 61.9 & 69 \\
\hline $135^{\circ}$ & $70 \cdot 0$ & 57 & 81.0 & 61 \\
\hline $180^{\circ}$ & 51.0 & 35 & 62.0 & 43 \\
\hline
\end{tabular}

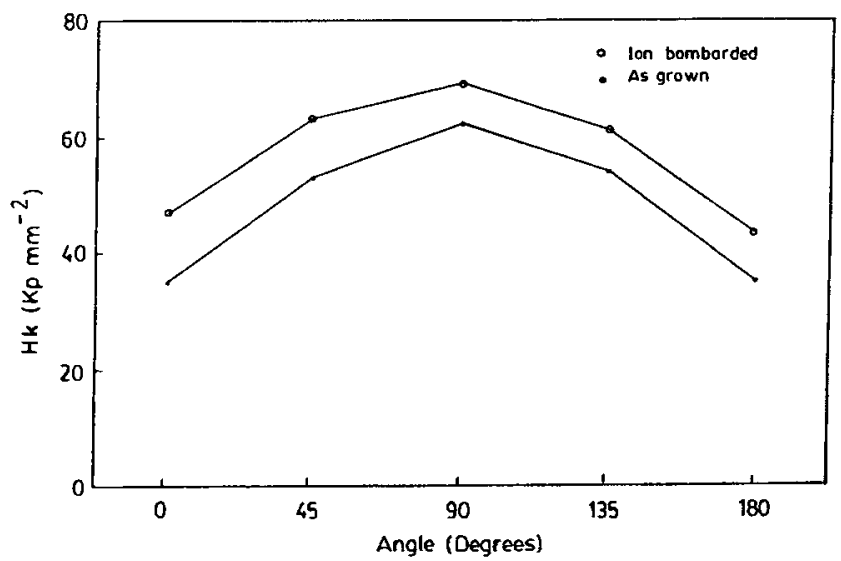

Figure 2. Planar plastic anisotropy of (001) face in as-grown and ion bombarded EDS single crystal using Knoop's indentor. 


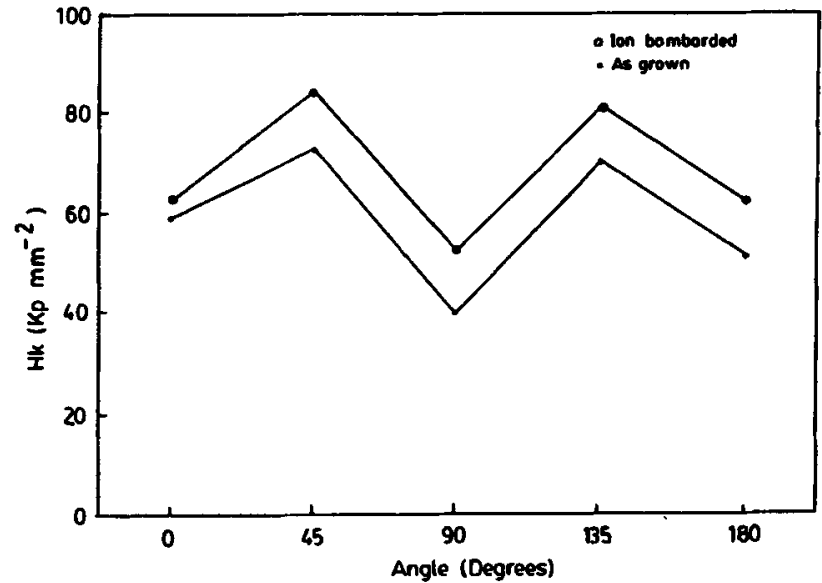

Figure 3. Planar plastic anisotropy of the (100) face of EDS crystal using Knoop's indentor.

vs $1 / T$ (shown in figure 4) reveal an enhancement of conductivity at all observed temperatures on ion implantation of EDS. The C-S bond strength being low relative to $\mathrm{C}$ $\mathrm{N} / \mathrm{C}-\mathrm{H}$ bond strengths, the probability of formation of $\mathrm{SO}_{4}^{-}$ions is high. Further the mobility of these ions is relatively high as the temperature is increased and the process is hastened by ion implantation. Thus, the increase in electrical surface conductivity on ion implantation and the subsequent thermal stimulation, may be due to migration and an increase in the concentration of $\mathrm{SO}_{4}^{-}$ions, on ion-bombardment of EDS.

The experimental results clearly indicate the drastic modification of the surface properties on ion implantation of EDS single crystal surfaces. Changes in surface morphology, defect substructure, dislocation density, microhardness and surface conductivity have also been noticed in EDS on ion implantation.

\section{Acknowledgements}

The authors thank the Inter University Consortium-

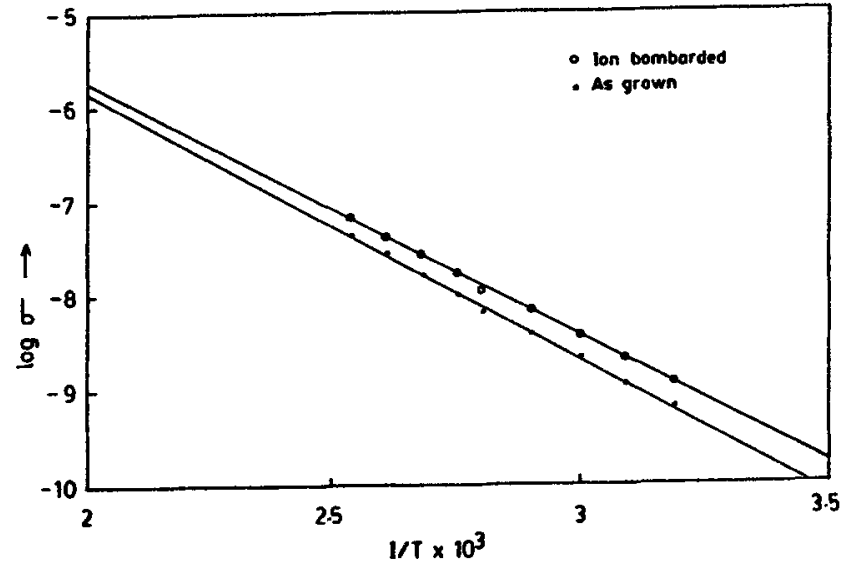

Figure 4. Arrhenius plots for the as-grown and $\mathrm{He}^{+}$ion bombarded EDS single crystal.

Department of Atomic Energy Facilities, Indore, for funding the research project, and the Indira Gandhi Centre for Atomic Research, Kalpakkam, for facilities provided for ion implantation.

\section{References}

Hassan F 1992 Studies on plastic flow under uniform and concentrated loads in some crystalline materials, Ph.D. thesis, Kakatiya University, Warangal

Kallman H and Silver M 1961 Electrical conductivity in organic solids (New York: Wiley) pp. 291

Mazzoldi P and Arnold G W 1987 in Ion beam modification of insulators (Amsterdam: Elsevier) pp. 301

Mott B W 1956 Microindentation hardness testing (London: Butterworths) pp. 63, 81

Runyan W R 1975 Semiconductor measurements and instrumentation (McGraw Hill)

Taylor G W and Simmons J G 1974 J. Phys. C7 3067

Williams D F and Schadt M 1970 Proc. IEEE 58475 